\title{
The obesity epidemic: can we turn the tide?
}

\section{Campbell}

Heart 2003;89(Suppl II):ii22-ii24

Obesity has reached epidemic proportions in the UK. It is important because of the associated co-morbidities, which include cardiovascular disease, type 2 diabetes, and osteoarthritis. The prevalence of obesity has increased because of a combination of excessive calorific intake (for example, from increased intake of energy dense foods) and insufficient energy expenditure (associated with a sedentary lifestyle). Weight loss of $5-10 \%$, which can be achieved in primary care, is associated with significant health benefits. Obesity treatment in primary care includes lifestyle modification and drug treatment. The prevention and treatment of obesity cannot, however, be left solely to health professionals. Action is needed by government, the food industry, and society as a whole.

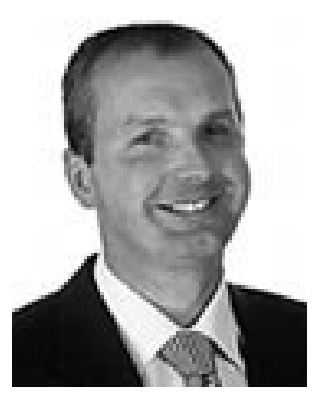

B efore considering the scale of the obesity problem in the UK, it is instructive to consider the trend in the development of obesity in the USA. In 1985, few states collected prevalence data as obesity was not seen to be an issue of interest. But over the years the problem developed and by 2000 about $20 \%$ of the US adult population was obese, defined as a body mass index (BMI) of $\geqslant 30 \mathrm{~kg} / \mathrm{m}^{2}{ }^{1}$. There is now great concern in the USA about the current level of obesity as it is now widely accepted that obesity is a disease in its own right and that it causes serious co-morbidities.

The UK is following a similar pattern and is now not far behind the USA. Obesity is already a disease of epidemic proportion, with the UK being known as the "fat man of Europe". In 1980, $8 \%$ of women and $6 \%$ of men in England were classified as obese. By 1998, the prevalence of obesity had nearly trebled to $21 \%$ of women and $17 \%$ of men. Currently, over half of women and about two thirds of men are either overweight (BMI $\geqslant 25 \mathrm{~kg} / \mathrm{m}^{2}$ ) or obese.

The problem of obesity is also becoming apparent in children, although there is as yet no consensus on how to define overweight and obesity in childhood. A population based study in
Liverpool $^{3}$ analysed routinely collected data from over 64000 children under the age of 4 years and defined overweight as a standard deviation score $>1.04$ for BMI ( $>85$ th centile) and obese as an SD of $>1.64$ (95th centile). They found that between 1989 and 1998 there was a highly significant increase in weight and BMI. The proportion of overweight children increased from $15 \%$ to $24 \%$ and the proportion of obese children from $5 \%$ to $9 \%$.

\section{CONSEQUENCES OF OBESITY}

Obesity is important because it substantially raises an individual's health risk (table 1), particularly from hypertension, dyslipidaemia, type 2 diabetes, coronary heart disease, stroke, gallbladder disease, osteoarthritis, sleep apnoea and respiratory problems, and endometrial, breast, prostate, and colon cancers (fig 1). ${ }^{45}$ Higher body weights are also associated with increases in all cause mortality. In addition, obese individuals may suffer from social stigmatisation and discrimination.

The relative risk of non-fatal myocardial infarction, fatal coronary heart disease, ${ }^{6}$ and type 2 diabetes increases as BMI increases. ${ }^{7}$ Figure 2 shows the effect of BMI on relative risk of cardiovascular disease in women. A man with a BMI of $32 \mathrm{~kg} / \mathrm{m}^{2}$ has an 11 -fold increased risk of type 2 diabetes compared with a man of normal weight, and a man with a BMI $\geqslant 35 \mathrm{~kg} / \mathrm{m}^{2}$ has a 40 -fold increased risk (fig 3). ${ }^{7}$ The relative risk associated with obesity is even higher in women. The association between body weight and diabetes is explained by the effects of fat on insulin resistance. It is now known that central (abdominal) obesity is the most dangerous form of obesity in terms of cardiovascular and metabolic risk. In addition to calculating BMI, it is therefore useful to measure waist circumference: a measurement of $\geqslant 88 \mathrm{~cm}$ in women and $\geqslant 102 \mathrm{~cm}$ in men is associated with increased risk of ill health. ${ }^{8}$

The cause of obesity is complex: genetic, biochemical, environmental, neurological, physiological, cultural, and socioeconomic factors can all be involved. As many as 250 genes are currently under investigation for their influence on obesity. It is thought that through evolution human beings have become "pre-programmed" to retain

Table 1 World Health Organization classification of overweight and obesity $(\mathrm{BMI}=$ weight $(\mathrm{kg}) /$ height $(\mathrm{m})^{2}$

Correspondence to: Dr lan Campbell, National Obesity Forum, PO Box 6625, Nottingham NG2 5PA, UK; icampbell@ nationalobesityforum.org.uk

\begin{tabular}{lll}
\hline Class & BMI $\left(\mathrm{kg} / \mathrm{m}^{2}\right)$ & Risk of comorbidity \\
\hline Underweight & $<18.5$ & Low \\
Normal range & $18.5-24.9$ & Average \\
Overweight (grade 1 obesity) & $25.0-29.9$ & Mild increase \\
Obese (grade 2 obesity) & $30.0-39.9$ & Moderate/severe \\
Morbid/severe obesity (grade 3) & $\geqslant 40.0$ & Very severe
\end{tabular}

Based on World Health Organization. Obesity: preventing and managing the global epidemic. Geneva: WHO, 1997. 


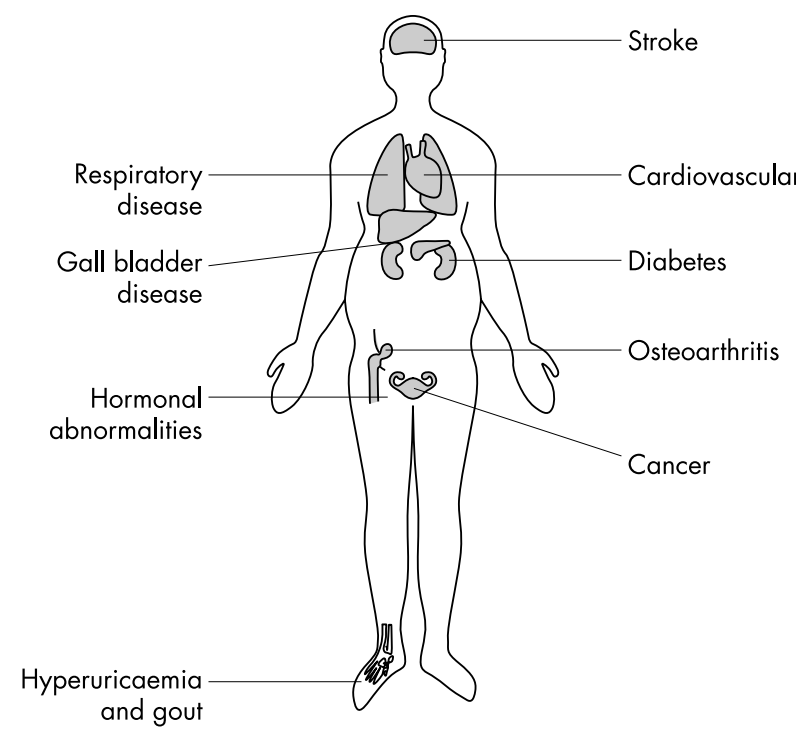

Figure 1 Physical effects of obesity.

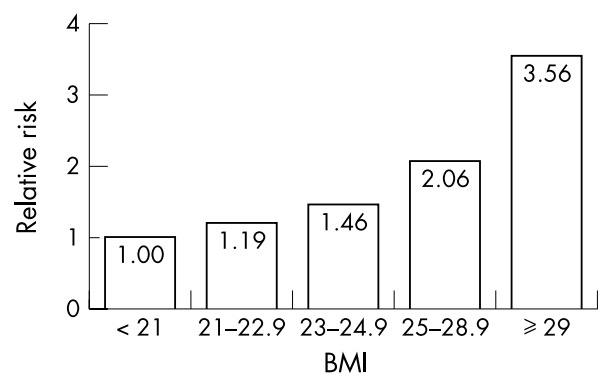

Figure 2 Relative risk of non-fatal myocardial infarction and fatal coronary heart disease (combined) versus body mass index (BMI) in women with no previous coronary heart disease. Adapted from Willett et al, ${ }^{6}$ with permission.

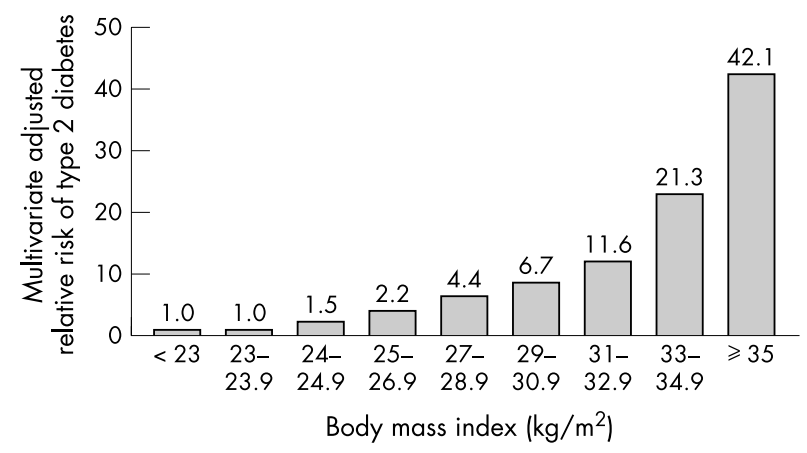

Figure 3 Relative risk of type 2 diabetes in men. Adapted from Chan et al, ${ }^{7}$ with permission.

fat: in times of hardship, those who survived the longest are likely to have been those who had extra weight. In the current times of plenty in the western world people are reacting normally to an abnormal environment. Obesity occurs because of excessive calorific intake (associated with increased access to energy dense foods and increased alcohol intake) and insufficient energy expenditure (associated with sedentary lifestyle).

\section{MANAGEMENT OF OBESITY}

The National Obesity Forum is a network for health care workers that promotes awareness of obesity, motivates and educates clinicians, and produces management guidelines (www.nationalobesityforum.org.uk). Tackling obesity is not,
Table 2 Benefits of $10 \mathrm{~kg}$ weight loss. Adapted from Jung, ${ }^{9}$ with permission

\begin{tabular}{ll}
\hline Mortality & $\begin{array}{l}20-25 \% \text { fall in total mortality } \\
30-40 \% \text { fall in diabetes related deaths } \\
40-50 \% \text { fall in obesity related cancer deaths }\end{array}$ \\
& $\begin{array}{l}\text { Fall of } 10 \mathrm{~mm} \mathrm{Hg} \text { systolic pressure } \\
\text { Fall of } 20 \mathrm{~mm} \mathrm{Hg} \text { diastolic pressure }\end{array}$ \\
& $\begin{array}{l}30-50 \% \text { fall in fasting glucose } \\
\text { Diabetes }\end{array}$ \\
Lipids & $\begin{array}{l}10 \% \text { decrease in total cholesterol } \\
15 \% \text { decrease in LDL } \\
30 \% \text { decrease in triglycerides } \\
8 \% \text { increase in } \mathrm{HDL}\end{array}$
\end{tabular}

HDL, high density lipoprotein; LDL, low density lipoprotein.

however, something that can be managed solely by health professionals. The prevention and treatment of obesity requires action by government, the food industry, and society as a whole. The problem has now been recognised by the government: the importance of managing obesity is recognised in the national service frameworks for both coronary heart disease and diabetes, and the National Institute of Clinical Excellence has published assessments of the anti-obesity drugs orlistat and sibutramine, and of weight reducing surgery. There is also now an all party parliamentary group on obesity and reports on obesity have been produced by the National Audit Office ${ }^{2}$ and the Public Accounts Committee. These reports are welcome as they indicate that increased attention is being paid to obesity and that the disease is likely to gain higher priority.

Obesity is a chronic disease with serious health consequences. Many overweight and obese patients are likely to have some form of cardiovascular disease, and weight management should form the first line of treatment. Lifestyle modification (dietary, physical activity, behaviour modification) is the key to management of obesity. However, anti-obesity medication also has a significant role to play in selected patients, as does surgery, although this is underfunded in the UK. A team approach to the management of obesity is required, and this should involve a wide range of health care staff, including doctors, nurses, dietitians, pharmacists, and psychologists. It is important to motivate the obese person, working with them to achieve and maintain weight loss. Blaming the individual is inappropriate and does not produce positive outcomes.

A general practitioner with an average list of 2000 patients is likely to have around 800 overweight adults (BMI $\geqslant 25 \mathrm{~kg}$ / $\left.\mathrm{m}^{2}\right), 320$ obese adults $\left(\mathrm{BMI} \geqslant 30 \mathrm{~kg} / \mathrm{m}^{2}\right)$, and 16 morbidly obese adults $\left(\mathrm{BMI} \geqslant 40 \mathrm{~kg} / \mathrm{m}^{2}\right)$. Ninety five per cent of these patients will see their general practitioner at least once every five years. Weight loss of $10 \mathrm{~kg}$, which can be achieved in primary care, is associated with significant health benefits (table 2). ${ }^{4}$ Success in weight management helps people to reduce their risk of disease and to improve the level of co-morbidity they already have. Even moderate weight loss (5-10\%), if it can be maintained, can improve co-morbid disease control, improve disease markers for cardiovascular disease, and lead to improved well being and self esteem, less breathlessness, less pain, and more energy.

\section{CONCLUSION}

Obesity is now a disease of epidemic proportions in the UK. It is a disease that has multiple causes and is not the patient's "fault". Obesity is one of the major risk factors for cardiovascular disease. It is preventable and treatable, and treatment is integral to the management of coronary heart disease and diabetes. Successful weight loss delivers substantial clinical benefit. 


\section{REFERENCES}

1 Mokdad AH, Bowman BA, Ford ES, et al. The continuing epidemics of obesity and diabetes in the United States. JAMA 2001;286:1 195-200.

2 National Audit Office. Tackling obesity in England. London: Stationery Office, 2001

3 Bundred P, Kitchiner D, Buchan I. Prevalence of overweight and obese children between 1989 and 1998: population based series of cross sectional studies. BM 2001;322:1-4.

4 National Heart, Lung, and Blood Institute, in cooperation with the National Institute of Diabetes and Digestive and Kidney Diseases. Clinical guidelines on the identification, evaluation, and treatment of overweight and obesity in adults: the evidence report. Bethesda Maryland: National Institutes of Health Publication No. 98-4083, September 1998.
5 Eckel RH. Obesity and heart disease: a statement for healthcare professionals from the Nutrition Committee, American Heart Association. Circulation 1997;96:3248-50.

6 Willett WC, Manson JE, Stampfer M, et al. Weight, weight change, and coronary heart disease in women. Risk within the 'normal' weight range. JAMA 1995;273:461-5.

7 Chan JM, Rimm EB, Colditz GA, et al. Obesity, fat distribution, and weight gain as risk factors for clinical diabetes in men. Diabetes Care 1994; 17:961-9.

8 Lean MEJ, Han TS, Seidell JC. Impairment of health and quality of life in people with large waist circumference. Lancet 1998;351:853-6.

9 Jung RT. Obesity as a disease. Br Med Bull 1997;53:307-21. 